\section{Association between proton pump inhibitors therapy and fracture risk in patients with rheumatoid arthritis}

Proton pump inhibitors are commonly prescribed for the treatment of acid-related gastrointestinal diseases. The association between proton pump inhibitors therapy and other subsequent comorbidities has been extensively explored. ${ }^{1}$ Recently, a cohort study in USA conducted by Ozen et al published in the Annals of the Rheumatic Diseases reported that proton pump inhibitors therapy was not associated with increased fracture risk in patients with rheumatoid arthritis (HR $=0.92 ; 95 \%$ CI 0.80 to 1.06$){ }^{2}$ Ozen et al's study is an important one and deserves a practical value. Some points not shown in the original article are shared with the readers. First, in order to test this issue in a different country, a preliminary population-based cohort study was conducted using the 2005-2012 database of the Taiwan National Health Insurance Program with 23 million residents living in Taiwan. ${ }^{3}$ Patients $\geq 20$ years old with a diagnosis of rheumatoid arthritis were included in the study. In order to reduce the biased results, those patients who had a cumulative periodof proton pump inhibitors therapy $<3$ months were excluded from the study. The main outcome was a new diagnosis of any major osteoporotic fractures including fractures of the spine, humerus, forearm, wrist and hip. Table 1 shows that the incidence of major osteoporotic fractures is 1.33 -fold higher in patients with proton pump inhibitors therapy than those without use, but it does not reach statistic significance (1.24 vs 0.94 per 100 person-years; $95 \%$ CI 0.86 to $2.06, p=0.2049$ ) which was compatible with Ozen et al's study reporting that no association could be observed between proton pump inhibitors therapy and fracture risk in patients with rheumatoid arthritis. ${ }^{2}$ Second, previous research has suggested that no significant association can be detected between proton pump inhibitors therapy and fracture risk in older adults. ${ }^{4}$ Ozen et al's and our studies further confirm that even in patients with rheumatoid arthritis, such an association still does not exist. Third, I agree with Sugiyama's comments published in the Annals of the Rheumatic Diseases reporting that no conclusive evidence supports a cause-effect relationship between proton pump inhibitors therapy and fracture risk, regardless of the population studied. ${ }^{5}$ Fourth, currently no research definitely proves that proton pump inhibitors therapy can change bone mineral density. So, the American Gastroenterological Association does not recommend that patients on long-time therapy of proton pump inhibitors need to routinely assess bone mineral density. ${ }^{6}$ Fifth, based on the above discussion, patients with rheumatoid arthritis who are on long-time therapy of proton pump inhibitors do not need to routinely examine bone mineral density and do not need to worry about fracture risk.

Shih-Wei Lai, ${ }^{\oplus 1,2}$ Yu-Hung Kuo, ${ }^{3}$ Kuan-Fu Liao ${ }^{4,5}$

${ }^{1}$ College of Medicine, China Medical University, Taichung, Taiwan

${ }^{2}$ Department of Family Medicine, China Medical University Hospital, Taichung, Taiwan

${ }^{3}$ Department of Research, Taichung Tzu Chi Hospital, Taichung, Taiwan

${ }^{4}$ College of Medicine, Tzu Chi University, Hualien, Taiwan

${ }^{5}$ Division of Hepatogastroenterology, Department of Internal Medicine, Taichung Tzu Chi Hospital, Taichung, Taiwan

Correspondence to Dr Kuan-Fu Liao; kuanfuliaog@gmail.com

Contributors S-WL contributed to the conception of the article, initiated the draft of the article and has approved the final draft submitted. Y-HK and K-FL conducted data analysis.

Funding The authors have not declared a specific grant for this research from any funding agency in the public, commercial or not-for-profit sectors.

Competing interests None declared.

Patient consent for publication Not required.

Provenance and peer review Not commissioned; internally peer reviewed.

(c) Author(s) (or their employer(s)) 2019. No commercial re-use. See rights and permissions. Published by BMJ.

\section{Check for updates}

To cite Lai S-W, Kuo Y-H, Liao K-F. Ann Rheum Dis Epub ahead of print: [please include Day Month Year]. doi:10.1136/annrheumdis-2019-215982

Received 3 July 2019

Accepted 5 July 2019

Ann Rheum Dis 2019;0:1. doi:10.1136/annrheumdis-2019-215982

\section{REFERENCES}

1 Jaynes $M$, Kumar $A B$. The risks of long-term use of proton pump inhibitors: a critical review. Ther Adv Drug Saf 2019;10.

2 Ozen G, Pedro S, Wolfe F, et al. Medications associated with fracture risk in patients with rheumatoid arthritis. Ann Rheum Dis 2019. doi:10.1136/ annrheumdis-2019-215328. [Epub ahead of print: 15 May 2019].

3 Ministry of Health and Welfare Taiwan. Taiwan health and welfare report, 2016. Available: http://www.mohw.gov.tw [Accessed cited on July 1, 2019, English version].

4 Harding BN, Weiss NS, Walker RL, et al. Proton pump inhibitor use and the risk of fractures among an older adult cohort. Pharmacoepidemiol Drug Saf 2018;27:596-603.

5 Sugiyama T. Association of proton pump inhibitors with fracture risk in patients with rheumatoid arthritis. Ann Rheum Dis 2019. doi:10.1136/annrheumdis-2019-215747. [Epub ahead of print: 31 May 2019].

6 Freedberg DE, Kim LS, Yang Y-X. The risks and benefits of long-term use of proton pump inhibitors: expert review and best practice advice from the American gastroenterological association. Gastroenterology 2017;152:706-15.

Table 1 Incidence of major osteoporotic fractures between proton pump inhibitors use group and non-use group in $\geq 20$ years old adults with rheumatoid arthritis, in 2005-2012

\begin{tabular}{|c|c|c|c|c|c|c|c|c|c|c|}
\hline \multirow[b]{2}{*}{ Variable } & \multicolumn{4}{|c|}{ Proton pump inhibitors use } & \multicolumn{4}{|c|}{ Non-use } & \multirow[b]{2}{*}{ Incidence rate ratio $(95 \% \mathrm{Cl})^{*}$} & \multirow[b]{2}{*}{$P$ value } \\
\hline & $\mathrm{N}$ & Event & Person- years & Incidence & $\mathrm{N}$ & Event & Person- years & Incidence & & \\
\hline All & 558 & 22 & 1760 & 1.24 & 5299 & 204 & 21690 & 0.94 & $1.33(0.86$ to 2.06$)$ & 0.2049 \\
\hline
\end{tabular}

Incidence:per 100 person-years.

*Incidence rate ratio: proton pump inhibitors use vs non-use $(95 \% \mathrm{Cl})$. 